\title{
National Academy of Medicine of Mexico posture with regard to end-of-life decisions
}

\author{
Armando Mansilla-Olivares, ${ }^{1}$ Joaquín López-Bárcena, ${ }^{1}$ Ricardo Plancarte-Sánchez, ${ }^{1}$ \\ Fermín Valenzuela-Gómez-Gallardo, ${ }^{1}$ Julieta Rojo, ${ }^{1}$ Fernando Meneses-González, ${ }^{1}$ \\ Gilberto Felipe Vázquez-De Anda, ${ }^{1}$ Patricio Santillán-Doherty, ${ }^{1}$ José Ignacio Santos-Preciado, ${ }^{1}$ \\ María de Jesús Medina, ${ }^{2}$ Asunción Álvarez ${ }^{3}$ and Beatriz Vanda ${ }^{4}$ \\ ${ }^{1}$ Academia Nacional de Medicina de México, Committee of Liaison and Dissemination of Knowledge; ${ }^{2}$ Universidad Nacional Autónoma de México, \\ Institute of Research on Law; ${ }^{3}$ Universidad Nacional Autónoma de México, Faculty of Medicine; ${ }^{4}$ Universidad Nacional Autónoma de México, Faculty \\ of Veterinary and Zootechnics, Ciudad de México, Mexico
}

\begin{abstract}
There are decisions at the end of life that currently are relevant as humanistic values. Respect for human life and dignity are part of human rights. The National Academy of Medicine of Mexico declares its posture about end-of-life decisions that include treatment refusal, limitation of the therapeutic effort, advance directives and palliative sedation, among others, with the purpose to favor a peaceful death.
\end{abstract}

KEY WORDS: End-of-life decisions. Treatment refusal. Limitation of the therapeutic effort. Advance directives. Palliative sedation.

Modern medicine is only regarded as scientific medicine: that which uses the knowledge of normal and pathological biological phenomena obtained and subjected to evaluation by means of scientific methodology with the purpose to favorably modifying them. However, medical activities always take place within the context of a relationship established by patients with their doctor, a relationship that generates inherent values its viability depends on: bonding, trust, empathy, veracity and reflection; in other words, profession. A profession that classically has been characterized as science and art. An art that involves the aforementioned humanistic values and that currently are reflected on respect for the dignity of human life from its beginning to its end through the inclusion of human rights.

On the other hand, the Objectives of Medicine recognize those dedicated to contribute to a peaceful death. However, there is a tendency to promote a discourse of objectives such as prevention, health preservation, healing, care of the sick ones, consolation and pain control; actions related to contribute to a peaceful death are dodged in the medical discourse.

\section{Dignified death}

The introduction of human rights has allowed highlighting the respect for human dignity even in the final events of life. It is important for dignified death to be understood as the continuation of a dignified life. In the context of medical care, the "way of dying" actually constitutes "the way to live the stage that precedes the loss of life", with the least possible suffering and from a perspective where the values and decisions of the dying person are respected. However, there is a debate of the medical, philosophical, anthropological, sociological and even political type around end of life and that complicates daily clinical work.

There is great confusion generated by the use of incorrect or confusing terms. In addition to this, neologisms are created that only contribute to confusion aggravation. This phenomenon has without a doubt ideological origins, but it totally lacks rational and reasonable foundations. It is important for the members that make up the health area to be able to manage a common language that allows clear and fluid
Gac Med Mex. 2018;154:628-631

Contents available at PubMed www.gacetamedicademexico.com 
communication when considering fulfillment of the last of the objectives of medicine: facilitating a peaceful death, a dignified death.

\section{Actions that are an integral part of medical care}

Every medical action must be the result of the deliberative process that occurs between patients and medical professionals, and the relationship between the stakeholders must therefore be protected and promoted. This dialectic interaction should generate such an exchange of information and dissipation of doubts as to allow a patient to make a decision about accepting or not accepting a proposed medical action. The informed consent process should be a natural result of a patient-doctor healthy relationship and not only be seen as an administrative-legal formality.

The final period of life occurs in very different forms and scenarios that establish the need to deal with it through different approaches. This is paramount in the process of care of patients with chronic-degenerative conditions that entail the possibility of developing irreversible harm with a quality of life that is difficult to cope with in a dignified way. Frequently, these actions generate confusion in the medical and non-medical field, where misinterpretations can make for them to be considered as aid or care omission, help/induction to suicide or euthanasia. It is important being able to communicate these different situations and their approaches, and it is therefore necessary for concepts that constitute an integral part of the duties of medical care to be clearly managed in the national health system:

- Refusal of treatment: It is the non-acceptance of proposed medical actions through the exercise of an autonomous decision based on the Patients' Bill of Rights and provided in the General Statute of Health.

- Therapeutic futility: It refers to those medical actions and therapeutic measures whose expected utility is none or close to none, which are considered to be "disproportionate" and beyond the patient's clinical context, and thus there is no moral obligation to maintain or to provide them.

- Limitation of the therapeutic effort: It is the non-initiation of therapeutic measures or discontinuation of those already initiated that, according to the specific clinical context of the patient and in the light of available medical evidence, are considered futile and, if anything, only manage to prolong biological life without the possibility of providing functional recovery with minimal quality of life.

- Advance directives: In a broad sense, it is those decisions a person (healthy or as a patient with an incurable, life-threatening or terminal disease) makes anticipating situations that he/she would or would not like to occur in terms of his/her medical care. It establishes provisions on organ and tissue donation for transplantation purposes and appoints a legally valid representative who can act as executor of the patient wishes, which can be expressed in two forms: a) when the patients is in full use of his/her mental faculties, informed and with communication skills, or, b) if the patient is unable to express him/herself, through a previously generated formal advance directives document. Should the patient not be able to express him/herself or have an advance directives document, a proxy decision making process should be generated, whereby an approach is sought to what the patient's unexpressed wishes might be, exploring the knowledge that on the subject the family, friends, acquaintances and important people in the patient's life (spiritual or religious counselors) might have in order to reach a vision that allows the proxy decision to be made by the responsible family member or legally accepted representative.

- Palliative care: It refers to active and total care of the patient who does not respond to a curative treatment, with special attention to pain, other physical and psychological symptoms, as well as to his/her spiritual needs. The care will be in charge of a multidisciplinary team and will include care to the family. Palliative care does not exclude curative treatments and, when required, it must be provided since the moment of diagnosis and continue in every moment, until the end of life.

- Palliative sedation: It is the administration of drugs to terminal patients and in the context of unsuccessful palliative care, with the purpose to reduce their state of consciousness, as much as necessary to alleviate symptoms that cannot be managed otherwise (mainly pain and dyspnea). It is accepted that it can precipitate life termination (usually by respiratory depression, hypercapnia and hypoxia), but this is not considered to be the purpose of sedation, since what is sought is to mitigate or reduce patient suffering (the moral principle of double effect). 


\section{Dignified death should generate an extended discourse}

The fact of recognizing the contribution to a peaceful death as an objective of medicine necessarily directs the discussion towards other forms of aid for dying under the concept of medically assisted death. These include modalities that are currently prohibited in our country, but that internationally have been legally accepted (euthanasia, assisted suicide and medically assisted suicide).

When palliative care can do no more to alleviate patient suffering, he/she should have the option, if that's his/her wish, to advance his/her death with adequate medical help, in full exercise of his/her autonomy and with the purpose to maintain his/her dignity as a person (and not in situations of irremediable despair as it occurs with palliative sedation).

The right to a dignified death, as a corollary of the right to a dignified life, now recognized in the Mexico City Constitution, establishes a legal basis to provide more legal certainty to health professionals' everyday work by recognizing medical actions that are already established in the laws of our country and that were specified at the beginning of this manuscript. In addition, it is the opportunity to progress towards the decriminalization of medically assisted death and being able to move towards a regulation that comprises euthanasia and medically assisted suicide as accepted forms of help to die which patients who wish may have access to.

\section{Conclusions}

The National Academy of Medicine of Mexico upholds the following position:

- That contributing to a peaceful death is one of the recognized goals of medicine, and hence it constitutes an ethical duty in health care.

- That end-of-life medical care requires a special strengthening of the patient-doctor relationship, in such a way that it favors maximum trust and allows autonomous decision making by attended patients.

- That health professionals should recognize the existence of medical actions and concepts at the end of life that are inherent to their daily work and are ethically and legally supported in our country (rejection of treatment, limitation of the therapeutic effort, therapeutic futility, advance directives, palliative care, palliative sedation, among others); these actions should be reinforced by regulatory considerations that offer greater legal certainty to health professionals.

- That the Academy should promote an open and sincere discussion, both within the medical community and in society in general, about end-of-life decisions in order for that which is already feasible with ethical and legal support to be known.

- That the Academy should promote an open and sincere discussion about medically assisted life termination aiming to explore its concepts, its decriminalization and its possible implementation as an alternative that guarantees the right to die with dignity.

\section{Glossary ${ }^{1}$}

Advance directives: It is an instrument by means of which a competent person establishes in writing his/ her wishes about the treatments he/she would and would not want to receive should he/she be in a situation where he/she cannot express his/her wishes by him/herself. Advance directives come into force when the person is no longer able to express his/her will.

Assisted suicide: It is the help a person gives to another who wants to terminate his life. The help is not restricted to the medical context. This means that the motive of the person who wants to die is not necessarily due to a disease; the help can be provided by any person and the used means can be medical or not.

Autonomy: Ability to voluntarily and without coercion make personal decisions and assume the consequences thereof. Autonomy assumes the capability to form a free judgement on that which is regarded as the best choice.

Basic care: It refers to hygiene, feeding and hydration measures, and, where appropriate, to the management of the airway provided by health personnel to a patient; however, the patient can refuse to be fed and hydrated, and this must be respected.

Cardiopulmonary resuscitation: Set of maneuvers intended to replace and restore spontaneous breathing and circulation in someone who has stopped breathing or whose heart has stopped beating, with the purpose for him/her to be able to survive.

Continuous and deep sedation until death: It describes the form of sedation given to a patient whose death is expected in less than two weeks, when alleviating his/her suffering has not been possible by other means. This sedation is accompanied by 
withdrawal of food and withdrawal or maintenance at minimal levels of hydration. It can precipitate life termination, but this is not the purpose of sedation, which is simply causing unconsciousness in order for the patient not to experience the suffering that cannot be alleviated during the time of life he/she has left.

Death: It is the permanent absence of an individual's cognitive relationship with him/herself and his/her environment, resulting from cardiac arrest or irreversible brain damage.

Dignity: Since this is an ambiguous term (it is equally used both to defend euthanasia and to attack it), it is preferable using the term in a subjective sense, i.e., based on what the patient establishes as minimally acceptable life conditions, which is what ultimately matters and that can be defined by the patient him/ herself.

Euthanasia: Etymologically, it means "good death", and it refers to the action a doctor performs to induce the death of a patient who has freely requested it for experiencing intolerable suffering that there is no relief for, which is caused by a disease or medical condition there are no therapeutic alternatives for. It is carried out using a painless method that produces rapid unconsciousness, followed by irreversible cardiorespiratory arrest.

Futility: Medical actions and therapeutic measures whose expected utility is none or close to none. Futile means are considered to be "disproportionate" and beyond the patient's clinical context, and thus there is no moral obligation to maintain them.

Limitation of the therapeutic effort: It is the discontinuation or non-initiation of treatments when according to medical evidence such treatments are useless or futile since they only manage to prolong biological life, delaying imminent death, but without the possibility of providing a functional recovery with a minimal quality of life.

Medically assisted suicide: It is the help a doctor gives a patient upon request, and it consists of providing the means for the patient to put an end to his/ her life. The help may consist in giving the patient a prescription for a lethal dose of medications or the medications themselves. The patient is the one who carries out the final action that causes his/her death.
Palliative care: It is the active and complete care of those patients who fail to respond to curative treatment, where providing relief through the treatment of pain and other symptoms, as well as the care of psychological, social and spiritual aspects, are the priorities.

Palliative sedation: It is the administration of drugs, at the required doses and combinations, to reduce the level of consciousness of a patient in a terminal situation, as much as necessary, with the purpose to relieve one or more symptoms that are not controllable with other measures and that cause him/her suffering or distress, administered with the patient consent or, if it is not feasible, with that of his/her family or representative.

Quality of life in the terminal patient: Concrete physical, psychological and social conditions that allow patients in a terminal situation to act in accordance to their objectives, expectations and beliefs, in the context of their family and social relationships.

Refusal of treatment: It is the power of every person to decide on the acceptance or not of interventions, procedures or treatments proposed by his/her doctors, even if the patient dies as a consequence of this decision. Just as in limitation of the therapeutic effort the weight of the decision falls on the doctor, the refusal of treatment falls on the patient.

Therapeutic obstinacy: Also called "therapeutic cruelty", it refers to the implementation or continuation of treatments or measures that are considered useless because they do not modify or improve the status of the patient and are able to prolong either physical, moral or even economic unnecessary suffering.

Voluntary rejection of food intake and hydration: It is the decision of a patient to stop consuming food and drinking water. It is a voluntary act carried out by the patient being aware of the consequences, and hence it rationally represents putting an end to his/her life.

\section{References}

1. Vanda-Cantón B. Conceptos básicos sobre la atención médica al final de la vida. En: Álvarez-Del Río A. La muerte asistida en México. Una opción más para morir con dignidad. México: Por el Derecho a Morir con Dignidad,; 2017. p. 119-125. 